\title{
Investigation of suitability of marbles to standards with inequality expressions and statistical approach using some physical and mechanical properties
}

\author{
Ozge Ozer ${ }^{1}$, Fusun Yalcin², Orhan Kemal Tarinc ${ }^{1}$ and Mustafa Gurhan Yalcin ${ }^{1 *}$
}

\section{"Correspondence: \\ gurhanyalcin@akdeniz.edu.tr 'Department of Geological Engineering, Akdeniz University, Antalya, Turkey \\ Full list of author information is available at the end of the article}

\section{黛 Springer}

\begin{abstract}
Marble, one of the metamorphic rock formation products, forms by undergoing different physical and chemical processes. The marble samples are tested under laboratory conditions to understand these processes. This study aims to find whether the Akcay region marble (Antalya) is compatible with national and international standards using some physical and mechanical properties. For this purpose, samples were subjected to some laboratory tests (real density, apparent density, total porosity, open porosity, breaking load, compressive strength, flexural strength, rupture energy). A number of statistical findings, linear equations, inequalities, and spatial distribution maps were obtained from the physical and mechanical data found at the end of the laboratory tests. The variables which were found to be statistically significantly correlated according to the results of the correlation analysis were analyzed using regression analysis; then their distributions were explained using linear equations. The spatial distribution maps of the variables reveal the part corresponding to the symbol color ranging between the light green and yellow and covering almost $70 \%$ of the area is compliant with both TurkStat and ASTM standards and this is proved using the inequalities.
\end{abstract}

MSC: $62 \mathrm{H} 10 ; 62 \mathrm{H} 25 ; 62-07 ; 60 \mathrm{E} 15 ; 62 \mathrm{H} 11$

Keywords: Statistical analysis; Inequalities expression; Physical property; Mechanical property; Marble

\section{Introduction}

There are karstifiable rocks in environments formed by the fault-crack joint system that dissolved and expanded under the influence of natural waters and the secondary openings. Carbonate rocks, which are a type of the karstifiable rocks, form various types of rocks in some physical and chemical environmental conditions. Being one of these types, marble is a metamorphic rock product that forms in the presence of minerals such as limestone, calcite, and aragonite. As a metamorphosed product, marble is a metamorphic carbonate rock. Determination of the physical and mechanical characteristics of the marble, which

(c) The Author(s) 2020. This article is licensed under a Creative Commons Attribution 4.0 International License, which permits use, sharing, adaptation, distribution and reproduction in any medium or format, as long as you give appropriate credit to the original author(s) and the source, provide a link to the Creative Commons licence, and indicate if changes were made. The images or other third party material in this article are included in the article's Creative Commons licence, unless indicated otherwise in a credit line to the material. If material is not included in the article's Creative Commons licence and your intended use is not permitted by statutory regulation or exceeds the permitted use, you will need to obtain permission directly from the copyright holder. To view a copy of this licence, visit http://creativecommons.org/licenses/by/4.0/. 
is a lithological unit, in addition to the initial and boundary conditions of it, is important for the process of "conceptualization and characterization of the mine". At first, the physical and mechanical properties of lithological units such as marble needs to be determined in terms of quality and usage. The determination of physical and mechanical properties such as real density, apparent density, total porosity, open porosity, breaking load, compressive strength, flexural strength, and rupture energy in laboratory/field conditions paves the way for mathematical modeling. Multivariate statistical analyses can be used to evaluate the characteristic features of marbles that have undergone different stages and tests. In the literature, some studies were conducted to evaluate and interpret tests on marble and rocks samples by using statistical analyses and inequality as methods [110]. Some of these studies are summarized as follows. In the study [11], the authors tried to understand the chemical formation mechanisms of marble samples by using chemical analysis data of marbles from Akcay village. Since the elemental distribution did not assume normality, they preferred using Spearman's rank correlation method, which is one of the multivariate statistical analyses. The compounds with the highest correlation $\mathrm{P}_{2} \mathrm{O}_{5}-$ $\mathrm{SrO}$ were determined using correlation analysis and tested using one-way ANOVA, one of the hypothesis tests. The marble samples that were collected from Akcay village were grouped under three codes and the one-way ANOVA $T$-test statistical method, one of the hypothesis tests, was used to understand the change between the samples. In another study [12], the authors compared the physical and mechanical properties of the marbles (Clova and Lyca) from Akcay village in Antalya using the independent sample $T$-test statistical method. In this study, the same physical and mechanical properties of samples from two different marble quarries in the same area were compared with each other. In the conclusion of this study, it was stated that the differences between the samples' physical and mechanical properties indicated different morpho-geological properties in the formation environment of marbles. Also, the contribution of the study, which obtained the properties of these two distinct marbles using statistical methods, to the literature is important in terms of sustainable use and purpose of usage objectives. In the study [13], the researchers applied various physical and mechanical tests to the samples taken from a beige marble quarry in Lyca and interpreted the relations of the test results using statistical analyses. They proposed a nonlinear model and an equation with $A=19.82 \mathrm{e}-0.0814$ for the relationship between abrasion resistance and Knoop hardness values, which are physical and mechanical data. This study is important for the literature because the abrasion resistance was estimated using the Knoop hardness value using this equation. It is important for the academic studies as well as the investors because the abrasion resistance value, which is also a physical and mechanical property, is a challenging issue to determine even in laboratory conditions and it requires a lot of labor and time, also, the error rate of the value might be quite high. On the other hand, the Knoop hardness value, which is also a physical and mechanical property, can be measured quite easily even under field conditions. In the study [14], the author used correlation analysis, which is one of the multivariate statistical methods, to determine the correlation between different types of physical and mechanical properties (UCAS, TS, BAV, grain size) of marble samples collected from five different locations. In this study, an equation, which can be assumed to be statistically significant with its $R^{2}$ value of 0.82 , was obtained for the relationship between uniaxial compressive strength and surface smoothness $(y=325.65 x+14.53)$. In this study, the author also obtained the equation of the negative correlation between grain sizes and 
surface smoothness of marble samples; however, the statistical significance of this equation was found to be low. Physical and mechanical properties of marbles are also essential and needed to prepare some other products for which marbles are used as an ingredient [15]. In the study [16], the researchers tested some of the physical and mechanical properties of marble samples. They formulated the correlation between the physical and mechanical properties by checking the normality of the distribution of these data by applying some statistical analysis. They concluded their study by stating the importance of these parameters for rock engineering. The study area, which lies between the Lyca nappes and Beydaglari Autochthonous, is suitable for marble formation in terms of both geological and topographic features. The aim of this study is to explain the properties affecting the quality of marble quarries by multivariate statistical methods and spatial distribution maps, showing as a result whether the marble is compatible with national and international standards.

\section{Methodology}

The phenomenon which results in a different geological formation by the metamorphosis of carbonate rocks such as limestone, calcite, or aragonite under natural environment conditions (the presence of a suitable soluble rock, water with a solvent feature, and a heterogeneous environment that can create a specific morphological structure) is called karstification and the new product is called marble [11]. The physical and mechanical analyses of the samples belonging to different locations of Akcay village marble quarry were made according to TurkStat's TS-EN 2513 standard. The physical tests carried out are real density, apparent density, total porosity (Eq. (1)), open porosity tests. Mechanical tests are listed as breaking load, compressive strength, flexural strength, rupture energy tests [17]. Multivariate statistical methods were used to analyze physical and mechanical data. A statistical analysis was carried out using the SPSS 23 software package by applying descriptive analysis and normality tests to physical and mechanical data. The data was analyzed to determine whether it is suitable for multivariate statistics or not. At the end of the analysis, the data was determined to be suitable for multivariate statistical analysis. Then correlation analysis, factor analysis (Kaiser-Meyer-Olkin, KMO and Bartlett's test; line plot, principal component analysis), classification (dendrogram), regression (linear distribution, model summary, and ANOVA analysis) were applied to the data. Regression analysis was applied to physical and mechanical properties which showed a high correlation. The equations and plots obtained by this analysis are examined and checked addressing whether they are statistically significant or not. Distribution maps were prepared with the same data using ArcMap 10.3.1 software and the results were examined as to whether they were compatible with high correlation. The data showing high correlation, their compatibility with national (TurkStat, 10449 1992) and international (ASTM, C503) standards were used in an attempt to find an explanation using inequalities in the study. Physical and mechanical properties were calculated as follows:

$$
n_{e}=\frac{V_{b}}{V_{t}} .
$$

Other physical and mechanical tests were carried out under laboratory conditions, thus, the values of breaking load, compressive strength, flexural strength, and rupture energy of 
the marble were revealed. The physical and mechanical analyses were conducted according to TurkStat's TS-EN 2513 Standard. The basic principle of compressive strength and breaking load tests is applying load on the samples using a compression machine with a capacity of up to $3000 \mathrm{kN}$ and obtaining the load value at which the samples begin to break or crack; see Eq. (2). The unit of the compressive strength is kg [18]. We have

$$
\sigma_{b}=\frac{P}{A}
$$

where $\sigma_{b}$ denotes compressive strength $\left(\mathrm{kg} / \mathrm{cm}^{2}\right), P$ denotes break load $(\mathrm{kg})$, and $A$ denotes the cross-sectional area of the sample $\left(\mathrm{cm}^{2}\right)$.

The energy applied to the marble sample under the influence of external forces to break a unit volume from the sample is called the rupture energy, (Eq. (3)) which is mathematically stated thus [19]:

$$
E_{c r}=\int_{0}^{E_{c r}} \tau\left(\varepsilon_{i}\right) d \varepsilon_{i}
$$

In the study [20], the researchers state that they collected the marble samples from the field in a plate form to apply the flexural strength test (Eq. (4)). They argue that if these plates meet certain standards it greatly affects the quality and use of marble. The flexural strength defines the form of the plates with certain inclinations and directions and their resistance to breaking [21]. We have

$$
F=\frac{3 P L}{2 b h^{2}}
$$

The flexural strength is defined as the maximum stress that corresponds to the strength value applied to the marble sample under elastic conditions and it is calculated at the lower point of the sample.

\section{Main results and discussion}

Multivariate statistical methods were used to reveal physical and mechanical properties (real density, apparent density, total porosity, open porosity, breaking load, compressive strength, flexural strength, rupture energy) of samples collected from the field (Tables 13). The physical and mechanical properties of the collected samples are quantitative data sets. The data was examined using Kolmogorov-Smirnov and Shapiro-Wilk tests to determine whether it showed the normal distribution (Tables 2-4).

Table 1 The results of the descriptive statistics of the physical data

\begin{tabular}{lcccc}
\hline & Real density & Apparent density & Total porosity & Open porosity \\
\hline Mean & 2763.33 & 2263.5 & 17.517 & 8.417 \\
Median & 2762 & 2273 & 17.05 & 8.2 \\
Variance & 8.667 & 1530 & 2.374 & 1.322 \\
Std. deviation & 2.944 & 39.119 & 1.5407 & 1.1496 \\
Minimum & 2760 & 2209 & 15.8 & 7.2 \\
Maximum & 2767 & 2305 & 20.1 & 10.6 \\
Range & 7 & 96 & 4.3 & 3.4 \\
Skewness & 0.64 & -0.447 & 0.997 & 1.668 \\
Kurtosis & -1.642 & -1.853 & 0.579 & 3.765 \\
\hline
\end{tabular}


Table 2 The table of the normality test of the physical data

\begin{tabular}{llllllll}
\hline & \multicolumn{2}{l}{ Kolmogorov-Smirnova } & & & Shapiro-Wilk & & \\
\cline { 2 - 3 } & Statistic & $\mathrm{df}$ & Sig. & & Statistic & $\mathrm{df}$ & Sig. \\
\hline Real density & 0.341 & 6 & 0.028 & & 0.804 & 6 & 0.064 \\
Apparent density & 0.259 & 6 & 0.200 & & 0.904 & 6 & 0.395 \\
Total porosity & 0.273 & 6 & 0.182 & & 0.921 & 6 & 0.516 \\
Open porosity & 0.339 & 6 & 0.030 & & 0.819 & 6 & 0.087 \\
\hline
\end{tabular}

Table 3 The results of the descriptive statistics of the mechanical data

\begin{tabular}{llccc}
\hline & Breaking load & Compressive strength & Flexural strength & Rupture energy \\
\hline Mean & 0.149183 & 51.17 & 4.95 & $3.3435 \mathrm{E}-06$ \\
Median & 0.1424 & 49 & 2.85 & 0.00000351 \\
Variance & 0.002 & 242.167 & 26.063 & 0 \\
Std. deviation & 2.944 & 15.562 & 5.1052 & $5.2617 \mathrm{E}-07$ \\
Minimum & 0.1033 & 35 & 0.4 & 0.00000249 \\
Maximum & 0.2339 & 80 & 13.6 & 0.00000402 \\
Range & 0.1306 & 45 & 13.2 & 0.00000153 \\
Skewness & 1.562 & 1.486 & 1.213 & -0.689 \\
Kurtosis & 3.146 & 2.944 & 0.349 & 0.645 \\
\hline
\end{tabular}

Table 4 The table of the normality test of the mechanical data

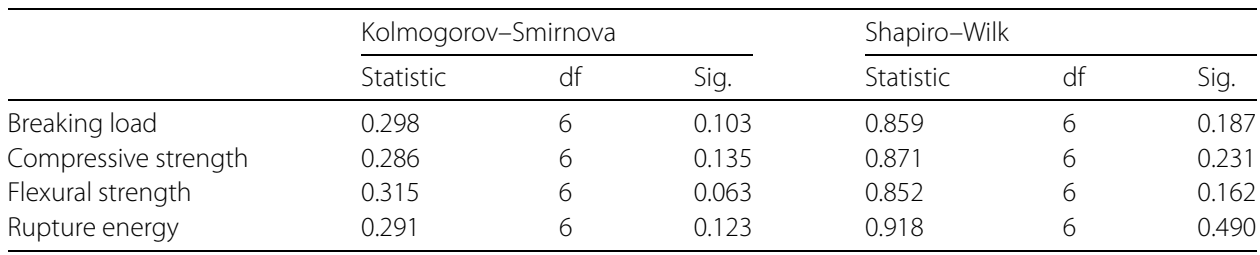

With an intuitive approach to the normality test, the results of the descriptive statistics revealed that the arithmetic mean and median values were close to each other and almost identical [22]. Then the tables of the Kolmogorov-Smirnov and Shapiro-Wilk tests were checked, and it was found that the $p$-values were greater than 0.05 and physical and mechanical analysis data (real density, apparent density, total porosity, open porosity, breaking load, compressive strength, rupture energy, flexural strength) were assumed to provide the normality assumption.

\subsection{Pearson correlation}

The Pearson correlation analysis (Eq. (5)), which is used for the data providing the assumption of a normal distribution, was conducted to reveal the relationship between the marble samples collected from Akcay village. We have

$$
r_{x y}=\frac{\sum_{\dot{I}=1}^{n}\left(x_{i}-\chi\right)\left(y_{i}-y\right)}{\sqrt{\sum_{i=1}^{n}\left(x_{i}-\chi\right)^{2}} \sqrt{\sum_{i=1}^{n}\left(y_{i}-y\right)^{2}}},
$$

where $n$ denotes the number of sample, $x_{i}$ and $y_{i}$ denote the separate samples spots indexed with $i, x$ and $y$ denote the means of the sample. The results of the applied analysis are given in Table 5. 
Table 5 Pearson correlation table of the physical and physical and mechanical properties of total porosity-open porosity and breaking load-compressive strength

\begin{tabular}{lllll}
\hline & Open porosity & Total porosity & Compressive strength & Breaking load \\
\hline Open porosity & 1 & & & \\
Total porosity & $0.851^{*}$ & 1 & & \\
Compressive strength & 0.238 & 0.203 & 1 & 1 \\
Breaking load & 0.223 & 0.181 & $0.998^{* *}$ & \\
\hline
\end{tabular}

Considering the Pearson correlation table, the positive correlations between the physical and mechanical properties of the total porosity and open porosity $\left(0.851^{*}\right)$ and between breaking load and compressive strength $\left(0.998^{* *}\right)$ were found to be high. When these figures were checked using the formulas in the literature (Table 5, Eqs. (1) and (2)), consistent results were obtained.

\subsection{Factor analysis}

The variance, which is one of the measures of variation of the descriptive statistics, is defined as the average of the squared differences from the arithmetic mean of the physical and mechanical observation values. The square root of the variance is defined as the standard deviation. The variance indicates the deviation of the physical and mechanical analysis data from the mean, i.e. how far from or close to the observation value from the average is [23]. It gives information about what percentage of the data can be explained by the statistical analysis [24]. Factor analysis is a multivariate analysis method in which the maximum variances of the correlated variables, which are obtained as the result of the correlation analysis, are found and summarized as a significant data [24]. Before performing a factor analysis, the suitability of the correlated variables for factor analysis is determined using the Barlett test and/or Kaiser-Meyer-Olkin (KMO) test [24]. The KMO test must meet the requirement of the measure of sampling adequacy $\geq 0.5$ [24-26] (Table 6).

The results of the KMO test reveal that the measure of sampling adequacy $>0.5(50 \%)$. The physical and mechanical properties of the marble samples from Akcay village meet the requirement of the measure of sampling adequacy for factor analysis. The result of the Barlett test is expressed with the significance value (Sig.) and it indicates a high correlation between the variables. In factor analysis, where variables are gathered around a maximum variance, the number of factors can be determined using a line plot (Fig. 1). The point where the inclination of the plot approaches 0 gives the number of the factors. It can be inferred that two factors summarize the data set.

According to the results of the proportion of variance explained table, which is provided by the eigenvalue statistics, it is determined that the number of factors is 2 , which is greater than 1. Factor 1 explains 49.955\% of the total variance explained while Factor 1 and Factor 2 together explain $96.250 \%$ of the total variance explained (Table 7).

Table 6 The result of the Kaiser-Meyer-Olkin (KMO) measure of sampling adequacy

\begin{tabular}{|c|c|c|}
\hline \multicolumn{3}{|l|}{ KMO and Bartlett's test } \\
\hline Kaiser-Meyer-Olkin measu & ng adequacy. & 0.500 \\
\hline Bartlett's test of sphericity & $\begin{array}{l}\text { Approx. chi-square } \\
\text { df } \\
\text { Sig. }\end{array}$ & $\begin{array}{l}20.282 \\
6 \\
0.002\end{array}$ \\
\hline
\end{tabular}


Table 7 The proportion of variance explained based on the eigenvalue statistics

\begin{tabular}{|c|c|c|c|c|c|c|c|c|c|}
\hline \multirow[t]{3}{*}{ Component } & \multicolumn{9}{|c|}{ Total variance explained } \\
\hline & \multicolumn{3}{|c|}{ Initial eigenvalues } & \multicolumn{3}{|c|}{$\begin{array}{l}\text { Extraction sums of squared } \\
\text { loadings }\end{array}$} & \multicolumn{3}{|c|}{$\begin{array}{l}\text { Rotation sums of squared } \\
\text { loadings }\end{array}$} \\
\hline & Total & $\begin{array}{l}\% \text { of } \\
\text { variance }\end{array}$ & $\begin{array}{l}\text { Cumulative } \\
\%\end{array}$ & Total & $\begin{array}{l}\% \text { of } \\
\text { variance }\end{array}$ & $\begin{array}{l}\text { Cumulative } \\
\%\end{array}$ & Total & $\begin{array}{l}\% \text { of } \\
\text { variance }\end{array}$ & $\begin{array}{l}\text { Cumulative } \\
\%\end{array}$ \\
\hline 1 & 2.168 & 54.208 & 54.208 & 2.168 & 54.208 & 54.208 & 1.998 & 49.955 & 49.955 \\
\hline 2 & 1.682 & 42.042 & 96.250 & 1.682 & 42.042 & 96.250 & 1.852 & 46.295 & 96.250 \\
\hline 3 & 0.149 & 3.714 & 99.964 & & & & & & \\
\hline 4 & 0.001 & 0.036 & 100.000 & & & & & & \\
\hline
\end{tabular}

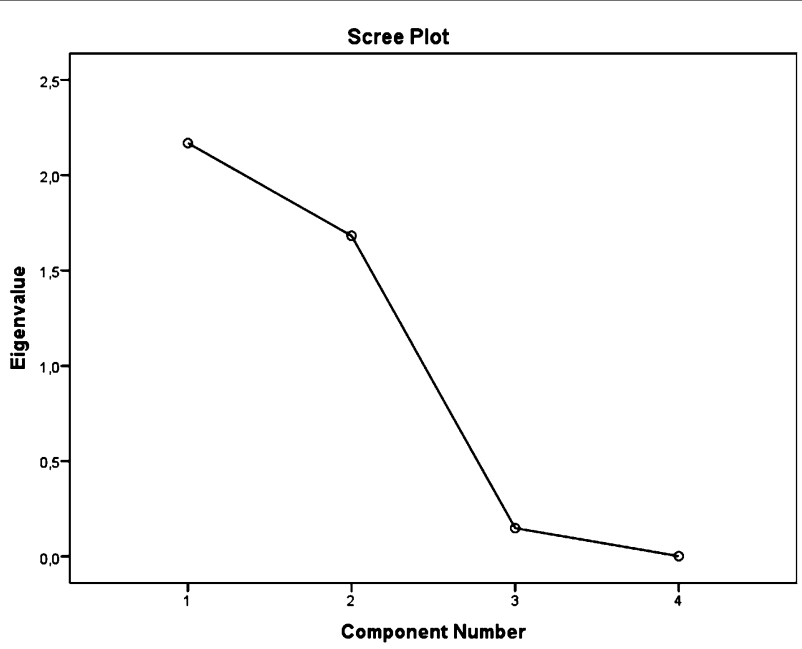

Figure 1 Line plot of factor analysis

\subsection{Classification}

All physical and mechanical analysis data of the marble samples from Akcay village were subjected to classification analysis, which is one of the statistical analyses. The analysis aims to classify the data according to their distribution and also to identify the quality and use area of marble, which is an industrial material, by using this classification, as well as to determine the marble options that can be extracted from the area (Fig. 2).

The results of the dendrogram analysis reveal that the marble samples can be classified into three groups $(1-6-2 ; 6-4 ; 4-5)$.

\subsection{Regression analysis}

The simple regression analysis can be defined as the explanation of the relationship between a dependent variable and an independent variable with a mathematical equation. If there is a linear relationship between the variables a linear regression method is used; if it is not a linear relationship, then a nonlinear regression method is used [24]. In a regression analysis, the coefficient of determination $R^{2}$ is calculated using Eq. (6)

$$
R^{2}=1-\frac{n-1}{n-p}\left(1-R^{2}\right)
$$

where $n$ denotes the number of sample, $p$ denotes the total quantity of explanatory variables in the formula. 


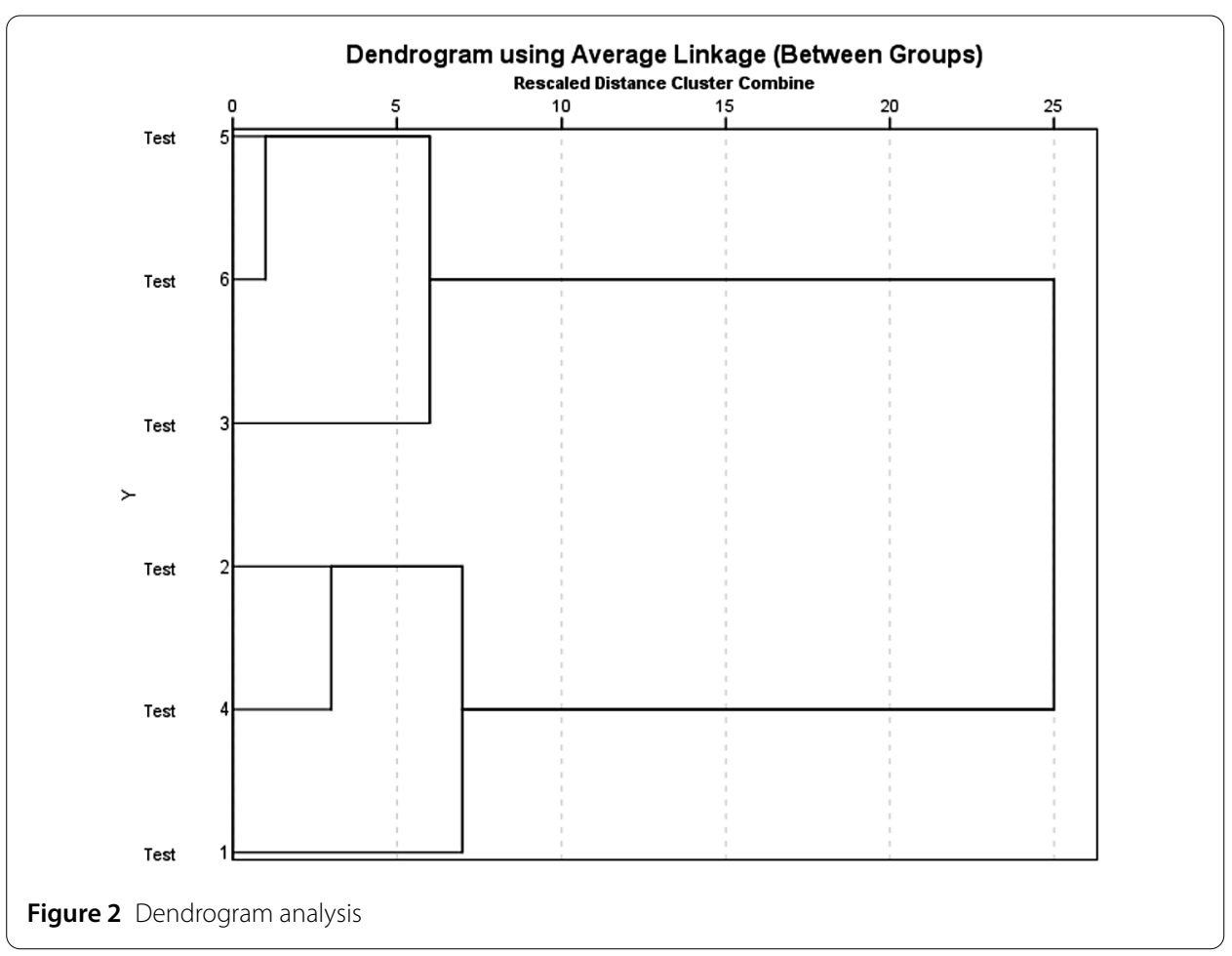

Four physical and mechanical properties of the marble samples from Akcay village were found to be correlated to a degree that could be considered statistically significant. Regression analysis was also used to explain these physical and mechanical properties. At this stage, the correlations between compressive strength and breaking load and between total porosity and open porosity were plotted. Their distributions were explained by the characterization of the linear equations (Figs. 3, 4; Tables 8-11).

In the analysis in which the physical and mechanical property of compressive strength is selected as dependent variable and the breaking load value is selected as the independent variable, the distribution of the data is explained by the linear equation Eq. (7)

$$
y=0.57+3.41 E 2 x,
$$

while the $R^{2}$ value is found to be 0.997 and the significance (Sig.) value is 0 . For $R^{2}$, the coefficient of determination (the proportion of the variance that is predictable), the table reveals that $99 \%$ of the compressive strength value can be explained by the breaking load value which also means that $99 \%$ of the breaking load value can be explained by compressive strength. The significance (Sig./ $p$-value) value in ANOVA analysis gives the percentage of error of the statistics [24]. The model we used to explain the relationship between compressive strength and breaking load or the relationship between breaking load and compressive strength is statistically significant.

In the analysis in which the physical and mechanical property of open porosity is selected as the dependent variable and the total porosity value is selected as the independent variable, the distribution of the data is explained by the linear equation (Eq. (8)) of

$$
y=-2.71+0.64 x
$$




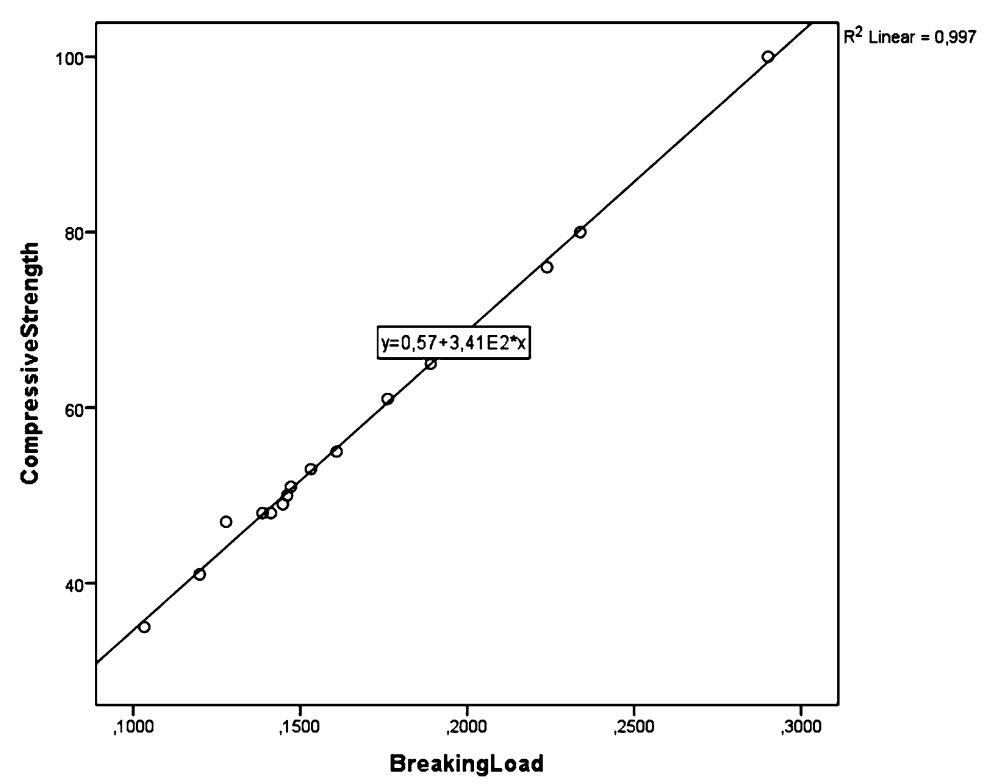

Figure 3 The linear distribution plot of the physical and physical and mechanical properties of load-compressive strength

Table 8 Coefficient of determination ( $R$ square) table of the physical and mechanical properties of breaking load-compressive strength

\begin{tabular}{lllll}
\hline Model summary & & & \\
\hline Model & $R$ & $R$ square & Adjusted $R$ square & Std. error of the estimation \\
\hline 1 & $0.998^{\mathrm{a}}$ & $\mathbf{0 . 9 9 7}$ & 0.997 & 0.965 \\
\hline
\end{tabular}

apredictors: (constant), breaking load.

bDependent variable: compressive strength.

Table 9 ANOVA table of the physical and mechanical properties of breaking load-compressive strength

\begin{tabular}{llccccc}
\hline ANOVA $^{\mathrm{a}}$ & \multicolumn{1}{c}{} & & \\
\hline Model & & Sum of squares & $\mathrm{df}$ & Mean square & $F$ & Sig. \\
\hline 1 & Regression & 3976.816 & 1 & 3976.816 & 4266.331 & $\mathbf{0 . 0 0 0 ^ { \mathrm { b } }}$ \\
& Residual & 12.118 & 13 & 0.932 & & \\
& Total & 3988.933 & 14 & & & \\
\hline
\end{tabular}

a Dependent variable: compressive strength.

bPredictors: (constant), breaking load.

while the $R^{2}$ value is found to be 0.725 and the Significance (Sig.) value is $0.32 . R^{2}$, the coefficient of determination table reveals that $72 \%$ of the open porosity value can be explained by total porosity value which also means that $72 \%$ of total porosity value can be explained by open porosity. The significance (Sig./p-value) value in the ANOVA analysis gives the percentage of error of the statistics [24]. The model we used to explain the relationship between porosity and total porosity or the relationship between total porosity and open porosity is statistically significant. 


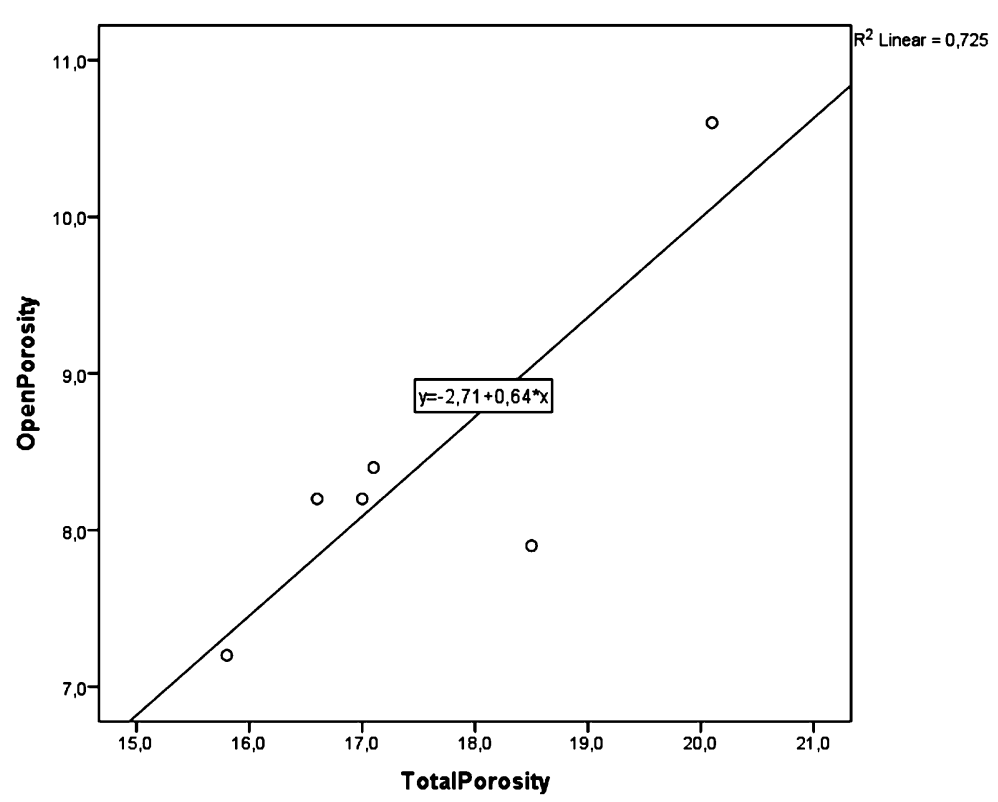

Figure 4 Linear distribution plot of the physical properties of total porosity-open porosity

Table 10 Coefficient of determination ( $R$ square) table of the physical and mechanical properties of total porosity-open porosity

\begin{tabular}{lllll}
\hline Model summary & & & \\
\hline Model & $R$ & $R$ square & Adjusted $R$ square & Std. error of the estimation \\
\hline 1 & $0.851^{\mathrm{a}}$ & $\mathbf{0 . 7 2 5}$ & 656 & 0.6746 \\
\hline
\end{tabular}

a Predictors: (constant), total porosity.

bependent variable: open prosity.

Table 11 ANOVA table of the physical and mechanical properties of total porosity-open porosity

\begin{tabular}{lllllll}
\hline ANOVA $^{\text {a }}$ & & & & & \\
\hline Model & & Sum of squares & df & Mean square & F & Sig. \\
\hline 1 & Regression & 4.788 & 1 & 4.788 & 10.522 & $\mathbf{0 . 0 3 2}^{\text {b }}$ \\
& Residual & 1.820 & 4 & 0.455 & & \\
& Total & 6.608 & 5 & & & \\
\hline
\end{tabular}

a Dependent variable: open porosity.

bPredictors: (constant), total porosity.

\subsection{Spatial distribution maps of the physical and mechanical properties}

The physical and mechanical properties of marble samples were combined with their geographical coordinates and their spatial distribution maps were prepared using ArcMap 10.3.1 software. The maps are given in Figs. 5-8. 
Figure 5 Spatial distribution map of the physical property of total porosity

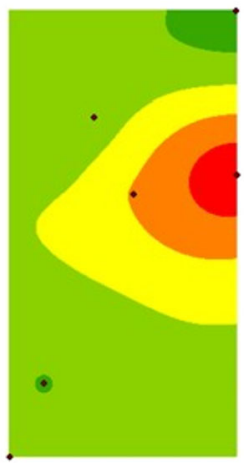

total_por

¿VALUE>

$15.80545616 \cdot 1666337891$

$16.66337892 \cdot 17.52130165$

$17.52130166 \cdot 18.3792244$

$18.37922441 \cdot 1923714714$

$19.23714715 \cdot 20.09506989$

Figure 6 Spatial distribution map of the mechanical property of breaking load
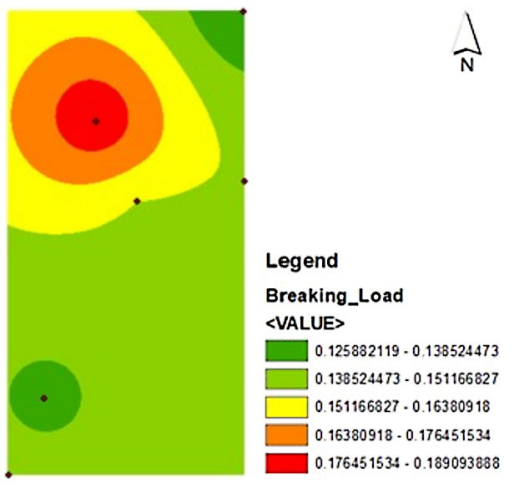

Figure 7 Spatial distribution map of the mechanical property of compressive strength
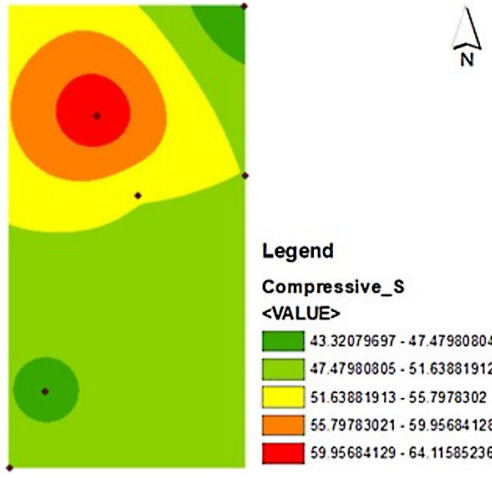

Legend

Compressive_s

〈VALUE>

43.32079697 - 47.47980804

$\square .47980805 \cdot 51.63881912$

$\square 51.63881913 \cdot 55.7978302$

$55.79783021 \cdot 59.9568412$

ए $59.95684129 \cdot 64.11585236$

Figure 8 Spatial distribution map of the physical property of open porosity

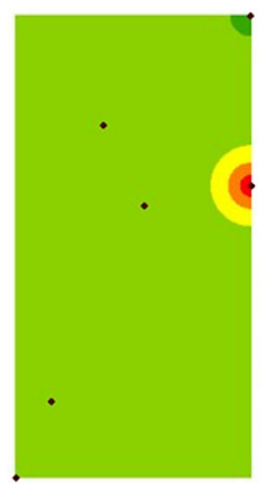

Legend

Open_Porosity

〈VALUE>

$7.214534223-7.888200378$

7888200379.8561866474

8.561866475 - 923553257

$9.235532571 \cdot 9.909198666$

9.909198667 - 10.58286476 
Table 12 Required values for Turkstat and ASTM standards classified according to the purpose of use of the marble [27-29]

\begin{tabular}{|c|c|c|c|c|}
\hline $\begin{array}{l}\text { Physical and } \\
\text { mechanical property }\end{array}$ & Purpose of & $\begin{array}{l}\text { Akcay } \\
\text { Marble }\end{array}$ & TurkStat (10449 1992) & ASTM (C503) \\
\hline Compressive strength & $\begin{array}{l}\text { Structural } \\
\text { Coating }\end{array}$ & 51.17 & $\begin{array}{l}7117.7 \text { psi (49 MPa) } \\
4267 \text { psi (29.4 MPa) }\end{array}$ & $\begin{array}{l}7500 \text { psi (52 MPa) } \\
4267 \text { psi (29.4 MPa) }\end{array}$ \\
\hline Flexural strength & $\begin{array}{l}\text { Structural } \\
\text { Coating }\end{array}$ & 4.95 & 870.25 psi (5.99 MPa) & 870.25 psi (5.99 MPa) \\
\hline Total porosity & - & 0.1751 & $\% 0.0002-0.5$ & $\% 0.0002-0.5$ \\
\hline
\end{tabular}

\subsection{Inequality statement}

Marble, which is classified as natural stone, has various physical and mechanical strength properties based on the location due to its metamorphic formation. The greatest effect of these properties on marbles is that it changes the quality and usage of the marble. In Turkey, the Turkish Standards Institute (TurkStat) has established a standard based on the ASTM C503 standard. The related TurkStat standard for marble, which has a metamorphic origin, is TS 104491992 [27]. This standard was used to evaluate four physical and mechanical properties of the marbles from Akcay village (Table 12).

The compressive strength of Akcay marble for structural and coating purposes (Eq. (9)) is

$$
\begin{aligned}
\sigma_{b} & =\frac{P}{A}, \\
\sigma_{b} & =51.17 \mathrm{MPa}:
\end{aligned}
$$

$52 \mathrm{MPa}$ (carriage ASTM) $\geq 51.17 \mathrm{MPa}$ (compressive strength of Akcay marble for structural use) $\geq 49 \mathrm{MPa}$ (carriage TSE);

$51.17 \mathrm{MPa}$ (compressive strength of Akcay marble for coating use) $\geq 29.4 \mathrm{MPa}$ (coating TurkStat)and 29.4 MPa (coating ASTM) (flexural strength of Akcay marble) (Eq. (10)). We have

$$
F=\frac{3 P L}{2 b h^{2}}
$$

$F=4.95 \mathrm{MPa} 5.99 \mathrm{MPa}$ (structural TSE,ASTM) and 5.99 MPa (coating TurkStat,ASTM) $\geq$ $4.95 \mathrm{MPa}$ (flexural strength of Akcay marble) (total porosity of Akcay marble) (Eq. (11));

$$
n_{e}=\frac{V_{b}}{V_{t}}
$$

$n_{e}=\% 0.1751 \% 0.0002-0.5$ (TurkStat and ASTM) \%0.1751 (total porosity of Akcay marble). Physical and physical-mechanical analysis results of marble samples were interpreted according to national standards. The above-mentioned inequalities have been removed in determining the quality and usage area of the marble. The relationship between the analysis results of marbles and the standards is clearly expressed with the inequalities identified above. A statistical interpretation of physical and mechanical analysis results is frequently observed in the literature [30,31]. Several different mechanical properties affecting marble samples have been explained by multivariate statistical analyses [11-32]. The effects of a number of physical and mechanical properties of marble samples on surface roughness value have been discussed using multivariate statistical methods [14]. The mechanical 
properties of marble samples affecting fracture and crack systems have been examined and evaluated using several statistical methods [32]. Moreover, inequality studies on marbles have gained prominence in recent years [1-10]. Therefore, statistical methods selected for the evaluation of the physical and mechanical properties of marbles from Akcay village, inequalities, and the maps obtained using geographical information systems have been successfully used in line with the intended goal for the study.

\section{Conclusions}

The statistical analyses carried out in this study left us with the following conclusions. The results of Pearson correlation analysis for the data matrix that provides the assumption of a normal distribution reveals a high degree of positive correlation between the total porosity and open porosity $\left(0.851^{*}\right)$ and between breaking load and compressive strength $\left(0.998^{* *}\right)$, which are physical and mechanical properties. These data, which are found to be correlated with each other, were examined using factor analysis (the analysis of the percentage of variance explained) and two factors were found to be greater than 1. Factor 1 explains 49.955\% of the total variance explained, while Factor 1 and Factor 2 explain $96.250 \%$ of the total variance explained. The results of the dendrogram analysis reveal that there are three major groups of marbles from Akcay village. Spatial distribution maps of physical and mechanical properties of marbles from Akcay village and inequalities can be interpreted together. According to TurkStat standards, the flexural strength value is expected to be $\geq 5.99 \mathrm{MPa}$ and, according to ASTM standards, the flexural strength value is expected to be $\geq 5.99 \mathrm{MPa}$. At the end of this analysis conducted under laboratory conditions, the flexural strength value was determined to be $4.95 \mathrm{MPa}$ and it was revealed that Akcay marbles do not comply with TurkStat and ASTM (for marbles used for transportation and coating) in terms of flexural strength. The marble used for coating and transportation is expected to have a compressive strength value $\geq 49 \mathrm{MPa}$ according to TurkStat standards and a compressive strength value $\geq 52 \mathrm{MPa}$ according to ASTM standards. According to this application, compressive strengths work as $51.17 \mathrm{MPa}$. Considering the spatial distribution maps of the compressive strength values (Fig. 7), approximately $70 \%$ of the terrain corresponds to light green and yellow color range in accordance with TurkStat and ASTM standards. Total porosity values of marbles are expected to be between TurkStat and ASTM standards (0.0002-0.5\%) according to the purpose of use. Considering the spatial distribution map, total porosity values seem to be between these values.

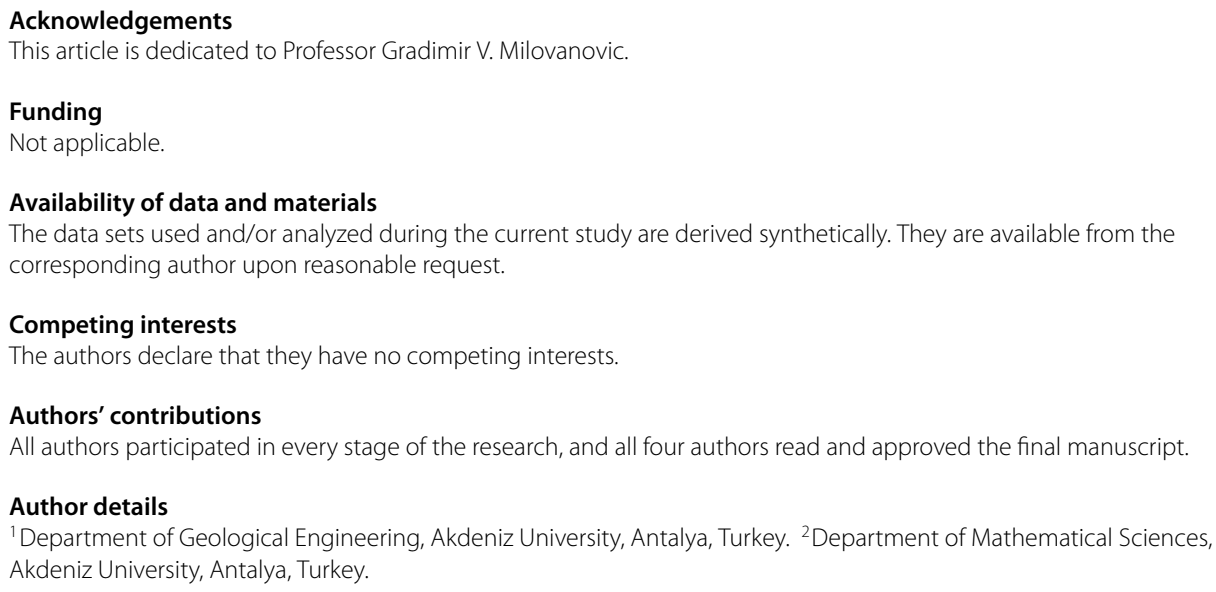




\section{Publisher's Note}

Springer Nature remains neutral with regard to jurisdictional claims in published maps and institutional affiliations.

\section{Received: 20 February 2020 Accepted: 25 March 2020 Published online: 07 April 2020}

\section{References}

1. Clark, A., Johnson, A., Mathews, D.: The gendered language of gravestones: a comparative study of central and northern Appalachian cemeteries. In: Handbook of the Changing World Language Map, pp. 1839-1851 (2020). https://doi.org/10.1007/978-3-319-73400-2-20-1

2. Schneider, P., Oswald, K.D., Riedel, W., Le Hung, A., Meyer, A., Nolivos, I., Dominguez-Granda, L.: Best practice for responsible small scale aggregate mining in developing countries. In: International Business, Trade, and Institutional Sustainability, pp. 529-553. Springer, Cham (2020). https://doi.org/10.1007/978-3-030-26759-9-31

3. Yalcin, F., Nyamsari, D.G., Ilbeyli, N., Battaloglu, R.: Statistical approach by factor and cluster analysis on the origin of elements from the Hamit Plutonic (Turkey) rock samples. Bull. Miner. Res. Explor. Inst. Turk. 160(160), 163-175 (2019). https://doi.org/10.19111/bulletinofmre.502074

4. Foster, A.: The serial novel, nation, and utopia: an intratextual re-reading of Pauline Hopkins' of one blood; or, the hidden self. In: Race and Utopian Desire in American Literature and Society, pp. 41-58. Palgrave Macmillan, Cham (2019). https://doi.org/10.1007/978-3-030-19470-3-3

5. Yalcin, F., Kilic, S., Nyamsari, D.G., Yalcin, M.G., Kilic, M.: Principal component analysis of integrated metal concentrations of Bogacayi riverbank sediments in Turkey. Pol. J. Environ. Stud. 25(2), 471-485 (2016). https://doi.org/10.15244/pjoes/61009

6. Yalcin, M.G., Akturk, O., Paksu, E.: The contribution of west Mediterranean cities (Antalya, Isparta, and Burdur) to Turkey's natural stones-marble export. In: International Multidisciplinary Scientific GeoConference: SGEM: Surveying Geology Mining Ecology Management, vol. 2, pp. 875-880 (2016). https://doi.org/10.5593/SGEM2016/B12/S03.112

7. Yalcin, F., Nyamsari, D.G., Paksu, E., Yalcin, M.G.: Statistical assessment of the heavy metal distribution and contamination of beach sands of Antalya-Turkey: an approach to the multivariate analysis techniques. Filomat 30(4), 945-952 (2016). https://doi.org/10.2298/FIL1604945Y

8. Sambuelli, L., Calzoni, C.: Estimation of thin fracture aperture in a marble block by GPR sounding. Boll. Geofis. Teor. Appl. 51, 239-252 (2010)

9. Young, E.D., Morrison, J.: Relations among net-transfer reaction progress, $18013 \mathrm{C}$ depletion, and fluid infiltration in a clinohumite-bearing marble. Contrib. Mineral. Petrol. 111(3), 391-408 (1992). https://doi.org/10.1007/BF00311199

10. Brown, C.A., Carpenter, T.P., Kouba, V.L., Lindquist, M.M., Silver, E.A., Swafford, J.O.: Secondary school results for the fourth NAEP mathematics assessment: algebra, geometry, mathematical methods, and attitudes. Math. Teach. 81(5), 337-397 (1988)

11. Tarinc, O.K., Ozer, O., Yalcin, F., Yalcin, M.G.: Statistical evaluation of the chemical characteristics on marble in Akcay village (Elmali, Antalya) region. In: International Symposium on Advanced Engineering Technologies, Kahramanmaras, Turkey, 2-4 May 2019, pp. 1333-1338 (2019)

12. Tarinc, O.K., Ozer, O., Aydin, B., Yalcin, M.G.: Comparison of physical-mechanical properties of Clova and Lyca marbles in Akcay (Antalya) region by using independent-samples T-test statistics. In: The 2nd Mediterranean International Conference of Pure Applied Mathematics and Related Areas, Paris, France, August 2019, pp. $28-31$ (2019)

13. Aydin, B., Yalcin, F., Ozer, O., Yalcin, M.G.: Regression analysis and statistical examination of Knoop hardness on abrasion resistance in Lyca beige marbles. Filomat (Accepted 2020)

14. Karaca, Z: Relationship between the mechanical properties and the surface roughness of marble. Int. J. Mater. Res. 103(5), 633-637 (2012). https://doi.org/10.3139/146.110728

15. Kockal, N.U.: Behavior of mortars produced with construction wastes exposed to different treatments. Indian J. Eng. Mater. Sci. 22, 203-2014 (2015) http://nopr.niscair.res.in/handle/123456789/31508

16. Jiang, Q., Zhong, S., Cui, J., Feng, X.T., Song, L.: Statistical characterization of the mechanical parameters of intact rock under triaxial compression: an experimental proof of the Jinping marble. Rock Mech. Rock Eng. 49(12), 4631-4646 (2016). https://doi.org/10.1007/s00603-016-1054-5

17. Tarinc, O.K.: Block purchase and export of physical mechanical and chemical properties of Akcay village Elmalı (Antalya) region marble. Master of Science Thesis (2019)

18. Turkmenoglu, Z.F., Kilic, A.M., Depci, T.: Investigation of mechanical properties of self-compacting lightweight concrete produced using Van Pumice and waste marble dust. J. Cukurova Univ. Eng. Archit. Fac. 30(1), 105-116 (2015). https://doi.org/10.21605/cukurovaummfd.242809

19. Gaziev, E.: Rupture energy evaluation for brittle materials. Int. J. Solids Struct. 38(42-43), 7681-7690 (2001). https://doi.org/10.1016/S0020-7683(01)00037-3

20. Cardani, G., Meda, A.: Flexural strength and notch sensitivity in natural building stones: Carrara and Dionysos marble. Constr. Build. Mater. 13(7), 393-403 (1999). https://doi.org/10.1016/50950-0618(99)00035-5

21. Senturk, A., Gunduz, L., Tosun, Y.I., Sariisik, A.: Marble technology. Suleyman Demirel University, Faculty of Engineering and Architecture Mining Engineering, Isparta (1996)

22. Yalcin, F., Ulkutanir, Y., Ozer, O.: An empirical application for some parametric tests in statistical analysis: assessment of academic success. In: International Symposium on Advanced Engineering Technologies, Kahramanmaras, Turkey, 2-4 May 2019, pp. 146-151 (2019)

23. Gursakal, N.: Descriptive Statistics. Dora Publishing (2012)

24. Kalayci, S.: SPSS Applied Multivariate Statistical Techniques, vol. 5. Asil Publishing, Ankara (2010)

25. Sharma, S.: Applied Multivariate Techniques (1996)

26. Kaiser, M.O.: Kaiser-Meyer-Olkin measure for identity correlation matrix. J. R. Stat. Soc. 52, 296-298 (1974)

27. Buyuksagis, I.S., Gurcan, S.: Comparison of ASTM and TSE natural stone standards. Madencilik 44(1), 33-41 (2005)

28. Akcakoca, H., Uysal, O., Topal, l.: The importance of technical-mechanical specifications of marbles about the quality control process. In: 4th Marble Symposium in Turkey, MERSEM, pp. 475-497 (2003)

29. Yazici, I., Ozer, O., Yalcin, M.G.: The evaluation of physical and mechanical properties of Alanya (Antalya) region dark films by TurkStat standards. In: International Symposium on Advanced Engineering Technologies, Kahramanmaras, Turkey, 2-4 May 2019, pp. 1339-1344 (2019). ISBN: 978-975-6497-38-8 
30. Kockal, N.U.: Optimizing production parameters of ceramic tiles incorporating fly ash using response surface methodology. Ceram. Int. 41, 14529-14536 (2015). https://doi.org/10.1016/j.ceramint.2015.07.168

31. Kockal, N.U., Ozturan, T.: Optimization of properties of fly ash aggregates for high-strength lightweight concrete production. Mater. Des. 32, 3586-3593 (2011)

32. Wong, L.N.Y., Zhang, Y: An extended grain-based model for characterizing crystalline materials: an example of marble. Adv. Theory and Simul 1(8), 1800039 (2018). https://doi.org/10.1002/adts.201800039

Submit your manuscript to a SpringerOpen ${ }^{\circ}$ journal and benefit from:

- Convenient online submission

Rigorous peer review

Open access: articles freely available online

- High visibility within the field

- Retaining the copyright to your article

Submit your next manuscript at $\boldsymbol{\nabla}$ springeropen.com 